\title{
THE INFLUENCE OF ORGANIC FERTILISER PROTOTYPES WITH THE TRICHODERMA ON THE SANITARY AND ENZYMATIC CONDITIONS OF SOIL AND THE YIELD OF SPINACH (SPINACIA OLERACEA L.)
}

\author{
Wolna-MaruwKa, A. ${ }^{1 *}$ - Niewiadomska, A. ${ }^{1}-$ GrZyB, A. ${ }^{1}-$ Piechota, T. ${ }^{2}-$ SzCZeCH, M. ${ }^{3}$ \\ - RYCHLIK, P. ${ }^{4}$ \\ ${ }^{I}$ Department of General and Environmental Microbiology, Poznan University of Life Sciences, \\ Szydlowska 50, 60-656 Poznan, Poland \\ ${ }^{2}$ Department of Agronomy, Poznan University of Life Sciences, Dojazd 11, 60-656 Poznan, \\ Poland \\ ${ }^{3}$ Research Institute of Horticulture, Konstytucji 3 Maja 1/3, 96-100 Skierniewice, Poland \\ ${ }^{4}$ Long Island Horticultural Research and Extension Center, Cornell University, 3059 Sound Ave \\ Riverhead, NY 1190, USA \\ ${ }^{*}$ Corresponding author \\ e-mail: amaruwka@up.poznan.pl \\ (Received $13^{\text {th }}$ Oct 2019; accepted $12^{\text {th }}$ Feb 2020)
}

\begin{abstract}
A two-year study was conducted to find how mineral and organic fertilisation and Trichoderma sp. strains influenced the total count of molds, including Fusarium, Alternaria and Trichoderma genera, the biological index of fertility (BIF) and the yield of spinach (Spinacia oleracea L.). Eleven variants were used in a field experiment conducted on lessivè soil: a control sample, mineral fertilisation, organic fertilisation with manure and eight variants with tomato or onion waste composts. Some of them were inoculated with Trichoderma atroviride (T1) and/or T. harzianum (T2 and T3) isolates. The addition of manure resulted in the greatest increase in the total count of moulds in the soil. The highest BIF value was noted in the soil enriched with tomato compost and inoculated with both T1 and T2 strains. The count of Fusarium sp. was reduced the most in the soil fertilised with onion compost with the addition of T1 and T3 isolates. The greatest decrease in the count of Alternaria sp. was observed in the soil fertilised with compost inoculated with the T1 strain. The onion compost inoculated with Trichoderma T1 and T3 resulted in the highest yield of spinach, which was comparable to the one obtained after mineral fertilisation.
\end{abstract}

Keywords: pathogens, molds, soil, biofertiliser, plant

\section{Introduction}

Currently one of the main focuses in waste management and energy generation from biomass is to reduce the amount of plant waste produced and to reuse it properly, in accordance with the Regulation of the Minister of the Environment on Recycling R10 (Journal of Laws of 2015, item 132).

According to the data of the Central Statistical Office (Statistics Poland, 2018), the amount of waste generated in Poland increases every year and most of it is disposed of in landfills. In $201723 \mathrm{~kg}$ of biodegradable waste was generated per capita, whereas in 2010 it was $4.7 \mathrm{~kg}$. According to Minelgaite and Genovaite (2019), Germany, Italy and the United Kingdom are leaders in the production of this waste, whereas Poland ranks eighth.

Directive 2008/98/EC of the European Parliament and of the Council of 19 November 2008 is the main act specifying general requirements concerning waste management. This 
directive establishes a legal framework for handling waste within the community to protect the environment and human health by from the negative effects of waste generation and management. The current waste policy in the EU is a challenge for Poland because according to the Regulation of the Minister of the Environment of 25 May 2012 (Journal of Laws of 2012, item 676), by 2020 Poland will have to limit the amount of landfilled biodegradable waste to $35 \%$.

Adequate handling of organic waste, by composting, for example enables disposal of troublesome material and acquisition of a high-quality fertiliser product, which can be reintroduced to the environment (Journal of Laws of 2015, item 132).

During the composting process the thermophilic phase, when the temperature reaches $60-70^{\circ} \mathrm{C}$, guarantees effective hygienisation of the composted material, which is to be used as a carrier for moulds of the Trichoderma sp. genus entered into the soil, which are regarded as a biocontrol agent (López-Mondéjar et al., 2011; López-Bucio et al., 2015).

The Regulation of the Minister of Agriculture and Rural Development of 18 April 2013 (Journal of Laws of 2013, item 505) and Directive 2009/128/EC imposed the obligation to search for alternative methods of plant production so as to limit or completely eliminate chemical crop protection products and mineral fertilisers. Organic fertilisers inoculated with Trichoderma moulds, which are antagonistic to plant pathogens, seem to be an excellent solution (Smolińska et al., 2014; Wolna-Maruwka et al., 2017).

Mycoparasitism against plant pathogens is the most powerful biocontrol mechanism caused by filamentous fungi of the Trichoderma genus. According to John et al. (2010), Hermosa et al. (2011 and 2012), this phenomenon provides plants with biological protection against plant pathogens such as Fusarium sp., Pythium sp., Alternaria sp., Verticillium sp., Colletotrichum sp., Rhizoctonia solani, and Botrytis cinerea.

Trichoderma sp. also protect plants by producing substances which act as antibiotics. These are: gliotoxin, viridine, and peptide antibiotics (peptaibols): trichotoxins A and B, trichodecenins, trichocellins, trichorovins, alamentacins, trichorzianines $\mathrm{A}$ and $\mathrm{B}$, trichorzins $\mathrm{HA}$ and MA, tricholongins $\mathrm{BI}$ and BII, longibrachins, trichocongins, atroviridins A-C, neoatroviridins A-D, sesquiterpenoids, isonitriles, polyketides, purine alkyls, as well as metabolites containing the isocyanide group (Wojtkowiak-Gębarowska, 2006).

According to Smolińska et al. (2014), Colla et al. (2015) and Druzhinina et al. (2011), the antagonism exhibited by Trichoderma moulds also involves competing with plant pathogens for the place of colonisation and nutrients, as well as modification of environmental conditions through acidification and production of siderophores.

Apart from that, research has proved that fungi of the Trichoderma genus are capable of inducing systemic immunity of plants. Secondary metabolites released by Trichoderma hyphae, e.g. enzymatic proteins, as well as components of the cell wall of plants and of these filamentous fungi are the substances inducing systemic immunity (Mathys et al., 2012).

The aim of the study was to assess the influence of composts inoculated with three Trichoderma strains on the sanitary condition of soil, measured with the count of potentially pathogenic moulds of the Alternaria and Fusarium genera. Apart from that, the soil activity and yield of spinach were measured.

The research assumption was that Trichoderma strains in combination with organic fertilisation had positive effect on the sanitary condition of soil and significantly 
influenced the soil enzymatic activity, thus increasing the yield of crops. This treatment strictly follows the policy of integrated crop protection.

Currently the Polish market does not offer any organic fertilisers containing native Polish strains of Trichoderma sp. The development of an innovative fertiliser based on composted plant waste and isolates of Trichoderma fungi will promote the growth and development of plants. In consequence, it will result in development of the domestic and global biofertiliser management.

\section{Material and methods}

\section{Experimental design}

A two-year experiment (2013 and 2014) was located on a private farm in Lubosz, Commune of Kwilcz, Greater Poland Voivodeship, Poland.

The experiment was conducted on the following three Trichoderma isolates: $T$. atroviride (T1) and T. harzianum (T2 and T3), which were supplied by the Institute of Horticulture in Skierniewice, Poland. They were used for the inoculation of onion and tomato waste composts and then they were applied to the soil under spinach (Spinacia oleracea L.), Renegade F1.

The experimental composts were produced on a technical scale (in prisms with about 20 tonnes of input). Both the tomato waste compost and onion waste compost (mostly clusters, leaves, etc.) were mixed with wheat straw (about $10 \%$ added) and a small amount of pig manure $(5 \%)$.

When the thermophilic phase finished (the prism temperature was about $25^{\circ} \mathrm{C}$ ), the composts were inoculated with Trichoderma strains.

The output concentration of individual spores in the resulting suspension was measured by means of a haemocytometer under a light microscope (Zeiss). The following results were noted: strain $\mathrm{T} 1-3.9 \cdot 10^{8}, \mathrm{~T} 2-2.3 \cdot 10^{8}, \mathrm{~T} 3-3.1 \cdot 10^{8}$ spores per $1 \mathrm{ml}$. The composts were inoculated with a suspension of conidial spores concentrated at $10^{4}$ per $\mathrm{g}$ wet mass of compost. Therefore, after calculation each prism of the composted material was respectively inoculated with $512.01 \mathrm{ml}$ of T1 strain spore suspension, $869.21 \mathrm{ml}$ of $\mathrm{T} 2$ isolate, $645.16 \mathrm{ml}$ of $\mathrm{T} 3 \mathrm{strain}, 690.60 \mathrm{ml}$ of a T1+T2 mixture and $578.58 \mathrm{ml}$ of a $\mathrm{T} 1+\mathrm{T} 3$ strain suspension. These conidial spore suspensions were mixed in 51 of dechlorinated tap water and applied with a hand sprayer.

One month after the inoculation of the composts they were entered into the soil. The following amounts were applied: onion waste compost $-43 \mathrm{t} \mathrm{ha}^{-1}$ and tomato waste compost $-38 \mathrm{t} \mathrm{ha}^{-1}$. Apart from the aforementioned composts, pig manure fertilisation $\left(37 \mathrm{tha}^{-1}\right)$ and mineral fertilisation with nitrogen as urea $\left(90 \mathrm{~kg} \mathrm{~N} \mathrm{ha}^{-1}\right)$, with phosphorus as triple superphosphate $\left(40 \mathrm{~kg} \mathrm{P} \mathrm{ha}^{-1}\right)$ and with potassium as potassium salt $(182 \mathrm{~kg}$ $\mathrm{Kha}^{-1}$ ) were also applied in the experiment. All organic fertilisers entered into the soil were equivalent to $170 \mathrm{~kg} \mathrm{~N}^{-1}$.

The field research was conducted after harvest of winter burley, on typical haplic luvisols formed from light loamy sands, deposited in a shallow layer on light loam. The granulometric composition of the soil ranged from light clayey to strong sands deposited on light clays. Selected soil characteristics are shown in Table 1.

Experiment was designed as randomised complete block, with four replications and plot size $9.3 \mathrm{~m}^{2}(6 \times 1.55 \mathrm{~m})$. Spinach, v. Renegade F1, were planted by means of a manual, precision seed drill Terradonis JP-1, with 25 seeds $\mathrm{m}^{-2}$, at $40 \mathrm{~cm}$ row spacing. Planting was carried out of August 16, both years. 
Table 1. Chemical characteristics of the soil

\begin{tabular}{c|c}
\hline Pure components & Value $\left(\mathbf{m g ~ k g}^{-\mathbf{1}}\right)$ \\
\hline $\mathrm{N}$ & 94.0 \\
$\mathrm{P}$ & 36.01 \\
$\mathrm{~K}$ & 69.77 \\
$\mathrm{Mg}$ & 60.02 \\
$\mathrm{pH}$ KCl & 5.8 \\
\hline
\end{tabular}

Eleven fertiliser combinations were used in the experiment: 1 - control sample, no fertiliser, 2 - mineral fertiliser, 3 - manure, 4 - onion waste compost, 5 - onion waste compost inoculated with strain T1, 6 - onion waste compost inoculated with strain T3, 7 - onion waste compost inoculated with strains T1 and T3, 8 - tomato waste compost, 9 - tomato waste compost inoculated with strain T1, 10 - tomato waste compost inoculated with strain T2, 11 - tomato waste compost inoculated with strains T1 and T2.

Both in 2013 and 2014 soil samples for microbiological and biochemical analyses were collected at three periods (ten replications), according to the Polish standard PN - ISO 10381 - 2: 2007. Depending on the research year, the sample collection dates coincided with the pre-sowing phase $(15,16$ July $)$ - term I, crop emergence phase ( 8,9 August $)-$ term II and harvesting phase (3, 6 October) - term III.

At each term of analyses 20 representative soil samples weighing about $0.5 \mathrm{~kg}$ were collected with an Egner-Riehm soil stick from each experimental site at a depth of 0-20 cm. A collective sample was prepared in accordance with the recommendations of the Polish Standard: PN-ISO 10381-2: 2007. On collection the soil and plant samples were transported to the laboratory of the Department of General and Environmental Microbiology and the Department of Agronomy, Poznań University of Life Sciences for microbiological and enzymatic analyses and to estimate the spinach yield value.

\section{Soil microorganisms}

The total count of moulds as well as the counts of Trichoderma sp., Alternaria sp. and Fusarium sp. were measured in the experiments (in five replicates). The microorganisms were cultured with the plate method on solid substrates. Appropriate soil solutions were used and expressed as cfu g ${ }^{-1} \mathrm{DM}$ of soil. The count of molds in the medium was measured according to the procedure developed by Martin (1950), with $3.5 \mathrm{ml} \cdot 1^{-1}$ rose bengal and $0.1 \mathrm{~g} \cdot 1^{-1}$ aureomycin added. The plates were incubated for 6 days at a temperature of $25^{\circ} \mathrm{C}$. The count of Trichoderma sp. was measured with the plate method, on a modified Martin's medium with $0.05 \mathrm{~g} \cdot 1^{-1}$ chloramphenicol, $0.05 \mathrm{~g} \cdot 1^{-1}$ streptomycin, $0.29 \mathrm{~g} \cdot 1^{-1}$ metalaxyl and $0.01 \mathrm{~g} \cdot 1^{-1}$ PCNB (pentachloronitrobenzene) added. The plates were exposed to visible light and incubated for 7 days at a temperature of $24^{\circ} \mathrm{C}$. In order to confirm that Trichoderma sp. belonged taxonomically to the Trichoderma harzianum or Trichoderma atroviride species the fungal colonies were inoculated to a PDA substrate (Sigma Aldrich). They were initially identified with a microscope. Next, the identification was confirmed by means of fluorescent in situ hybridisation (FISH) (Amann et al., 1990) with 4\% PFA (paraformaldehyde), 0.5\% Triton solution, alcohol series (70\%, 80\%, 96\%), $70 \%$ formamide solution and two probes, whose ends were marked with $\mathrm{Cy} 3$ marker (ACT CCC AAA CCC AAT GTG AA and ATA CCA AAC TGT TGC CTCGG) (Siddiquee et al., 2010). 
In the experimental variants where the aforementioned Trichoderma sp. isolates were not applied, but native Trichoderma sp. strains were identified in the soil (e.g. in the control sample), only the counts of Trichoderma harzianum and Trichoderma atroviride were measured.

The count of Fusarium sp. was measured with the plate method, on a Komada medium (Komada, 1975) with $0.5 \mathrm{~g} \cdot \mathrm{l}^{-1}$ ox bile, $0.05 \mathrm{~g} \cdot \mathrm{l}^{-1}$ chloramphenicol, $0.3 \mathrm{~g} \cdot \mathrm{l}^{-1}$ streptomycin, $1.0 \mathrm{~g} \cdot 1^{-1}$ borax and $1.0 \mathrm{~g} \cdot 1^{-1}$ PCNB (pentachloronitrobenzene) added. The plates were incubated for 14 days at a temperature of $24^{\circ} \mathrm{C}$. The count of Alternaria sp. was measured on a medium developed by Hong and Pryor (2004). It was composed of $20 \%$ lactic acid, $0.005 \mathrm{~g} \cdot \mathrm{l}^{-1}$ botram (active ingredient: dichloran), $0.2 \mathrm{~g} \cdot \mathrm{l}^{-1}$ bayleton (active ingredient: triadimefon) and $0.3 \mathrm{~g} \cdot l^{-1}$ streptomycin. The plates were incubated at a temperature of $24^{\circ} \mathrm{C}$ for 7 days. The fungal colonies were inoculated to a PDA substrate (Sigma Aldrich). Next, they were identified taxonomically on the basis of mycological keys (Gerlach and Nirenberg, 1982; Chełkowski, 1989; Chełkowski and Visconti, 1992; Domsch et al., 1993).

\section{Soil enzymes}

Spectrophotometry was used for biochemical analyses. The dehydrogenase activity (DHA) was measured according to the procedure developed by Thalmann (1968), with some minor modifications. The soil ( $1 \mathrm{~g})$ with 2, 3, 5-triphenyltetrazolium chloride (TTC) was incubated for $24 \mathrm{~h}$ at $30^{\circ} \mathrm{C}, \mathrm{pH}$ 7.4. Triphenylformazan (TPF) was produced, extracted with $96 \%$ ethanol and measured spectrophotometrically at $485 \mathrm{~nm}$. The dehydrogenase activity was expressed as $\mu$ mol TPF $\mathrm{g}^{-1} \mathrm{DM}$ of soil $24 \mathrm{~h}^{-1}$.

The catalyse activity (CAT) in the soil was measured by means of titration (Johnson and Temple, 1964). The soil with $0.3 \% \mathrm{H}_{2} \mathrm{O}_{2}$ solution was incubated for 20 minutes. Next, $1.5 \mathrm{M} \mathrm{H}_{2} \mathrm{SO}_{4}$ was added. The resulting solution was titrated with $0.02 \mathrm{M} \mathrm{KMnO}_{4}$. The catalyse activity was expressed as $\mu \mathrm{mol} \mathrm{H}_{2} \mathrm{O}_{2} \mathrm{~g}^{-1}$ D.M. of soil $\mathrm{min}^{-1}$.

The dehydrogenases and catalyse activity were measured to determine the soil BIF (Biological Index of Fertility) (Eq. 1) (Stefanic et al., 1984):

$$
B I F=(1.5 D H A+100 k C A T) / 2
$$

where $\mathrm{k}-$ the proportionality coefficient $=0.01$.

\section{Crops}

The whole plant, aboveground biomass of spinach was harvested manually from two central rows in the plot for the yield measurement.

\section{Statistical analysis}

Statistica 12.0 software (StatSoft Inc., 2012) was used for statistical analyses. Two-way analysis of variance was used to determine the significance of variation in the count of groups of microorganisms and the soil enzymatic activity, depending on the soil combination and term of analysis. Homogeneous subsets of means were identified by means of Tukey's test at a significance level of $\mathrm{p}<0.05$.

The second step of the diagnostic procedure involved stepwise regression to determine the optimal set of variables for a given characteristic of the microorganisms. The best 
regression model was chosen on the basis of the highest F-value for the model and the significance of all the independent variables.

The relation between the count of microorganisms, soil enzymatic activity and the yield was illustrated by means of Principal Component Analysis (PCA).

\section{Results and discussion}

The analysis of the soil samples at the first term, i.e. before the application of the Trichoderma sp. strains, showed that these microorganisms were part of the natural, autochthonous soil microbiome (Table 2).

Table 2. The count of Trichoderma sp. in the soil with the fertilisers at the three terms of analysis

\begin{tabular}{c|c|c|c}
\hline & I $^{\text {st }}$ TERM & II $^{\text {nd }}$ TERM & III $^{\text {rd }}$ TERM $^{\text {TE }}$ \\
\hline Control & 0.00 & $5.38^{\mathrm{bc}}$ & 0.00 \\
MIN & $2.89^{\mathrm{a}-\mathrm{c}}$ & $3.83^{\mathrm{a}-\mathrm{c}}$ & $0.37^{\mathrm{a}}$ \\
MAN & 0.00 & $2.76^{\mathrm{a}-\mathrm{c}}$ & 0.00 \\
O & $0.73^{\mathrm{ab}}$ & $1.88^{\mathrm{a}-\mathrm{c}}$ & 0.00 \\
O1 & 0.00 & $3.06^{\mathrm{a}-\mathrm{c}}$ & 0.00 \\
O3 & 0.00 & $1.9^{\mathrm{a}-\mathrm{c}}$ & 0.00 \\
O1+3 & 5.00 & $5.7^{\mathrm{c}}$ & $1.86^{\mathrm{a}-\mathrm{c}}$ \\
T & $1.45^{\mathrm{a}-\mathrm{c}}$ & $1.54^{\mathrm{a}-\mathrm{c}}$ & $0.74^{\mathrm{ab}}$ \\
T1 & 0.00 & $1.88^{\mathrm{a}-\mathrm{c}}$ & $0.36^{\mathrm{a}}$ \\
T2 & 0.00 & $1.94^{\mathrm{a}-\mathrm{c}}$ & 0.00 \\
T1+2 & 0.00 & $1.18^{\mathrm{a}-\mathrm{c}}$ & $0.37^{\mathrm{a}}$ \\
\hline
\end{tabular}

Explanation: The means followed by the same letters do not differ significantly at $p=0.05$; Combination: Control - no fertiliser, MIN - mineral fertiliser, MAN - manure, $\mathrm{O}$ - onion waste compost, $\mathrm{O} 1$ - onion waste compost inoculated with strain $\mathrm{T} 1, \mathrm{O} 3$ - onion waste compost inoculated with strain $\mathrm{T} 3, \mathrm{O} 1+3-$ onion waste compost inoculated with strains $\mathrm{T} 1$ and $\mathrm{T} 3, \mathrm{~T}-$ tomato waste compost, $\mathrm{T} 1$ - tomato waste compost inoculated with strain T1, T2 - tomato waste compost inoculated with strain $\mathrm{T} 2, \mathrm{~T} 1+2-$ tomato waste compost inoculated with strains T1 and T2; Terms: I $^{\text {st }}-$ pre-sowing phase, II $^{\text {nd }}-$ crop emergence phase, III ${ }^{\text {rd }}$ - harvesting phase

According to Smolińska et al. (2014), these microorganisms are commonly found in all soil types around the world. They usually occur on the surface of roots. Only few species can penetrate deeper. Apart from that, Trichoderma sp. can quickly colonise the substrate by competing with other microorganisms for the place of colonisation and nutrients. This situation was observed at the second term of analyses. It is most likely that the intensive growth of Trichoderma sp. in that period was caused by a change in the qualitative and quantitative composition of spinach root secretions, which acted as attractants (Vallance et al., 2011).

On harvesting the plants (the third term) the count of Trichoderma sp. decreased sharply or was totally reduced, especially in the control variant (without fertilisation). Trichoderma sp. were found only in the variant where the mineral fertiliser had been applied, in the one with onion compost inoculated with two strains and in three variants enriched with tomato compost. The highest, but statistically insignificant count of these microorganisms was noted in the soil with the onion compost inoculated with both the T1 
and $\mathrm{T} 3$ strains $(\mathrm{O} 1+3)$. The rapid, but in most cases statistically insignificant decrease or total reduction in the count of Trichoderma sp. in the experimental variants may have been caused by more intense proliferation of the total count of molds (Fig. 1). This may have resulted in the occurrence of species inhibiting the growth and development of Trichoderma sp.

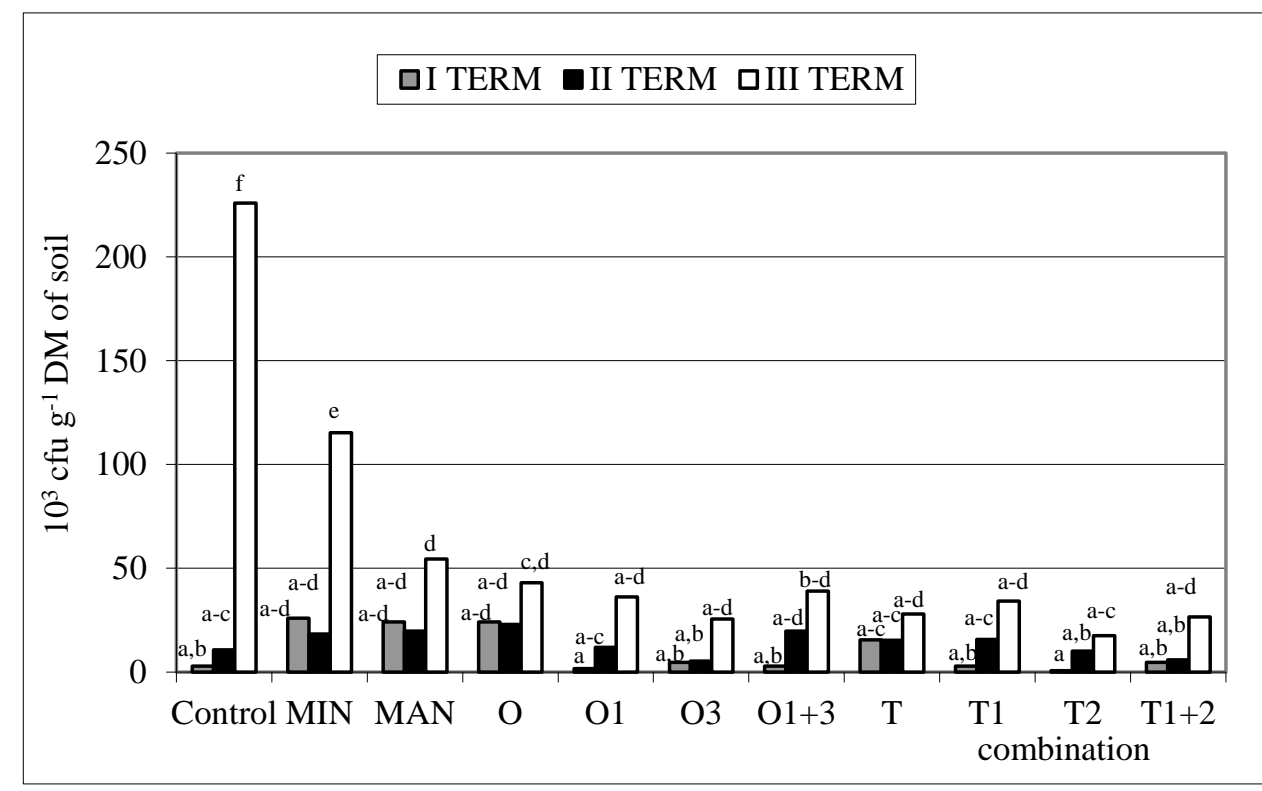

Figure 1. Changes in the total count of molds in the soil. Explanation: The means followed by the same letters do not differ significantly at $p=0.05$; Combination: Control - no fertiliser, MIN - mineral fertiliser, MAN - manure, $O$ - onion waste compost, OI - onion waste compost inoculated with strain T1, O3 - onion waste compost inoculated with strain T3, O1+3 - onion waste compost inoculated with strains T1 and T3, T-tomato waste compost, T1 - tomato waste compost inoculated with strain T1, T2 - tomato waste compost inoculated with strain T2, T1+2 - tomato waste compost inoculated with strains T1 and T2; Terms: $I^{\text {st }}$ - pre-sowing phase, II ${ }^{\text {nd }}$ crop emergence phase, III ${ }^{\text {rd }}$ - harvesting phase

According to Piegza et al. (2009), the fact that fungi of the Trichoderma genus exhibit poorer adaptation properties in vitro may be caused by their poorer ability to compete for nutrients and place of colonisation as well as their less abundant sporulation than some other species of fungi. Wawrzyniak and Waśkiewicz (2014) proved that some Penicillium species were capable of producing antibiotics and mycotoxins, e.g. ochratoxin A and citrinin, which inhibit the growth and development of other microorganisms, including Trichoderma.

The analysis of changes in the total count of molds during the experiment showed that the most intense colonisation of the soil with these microorganisms occurred particularly at the third term and at the second term of analyses and that it depended on the experimental variant (Fig. 1). There were statistically significant differences $(p=0.05)$ between the experimental variants in the count of moulds mainly at the plant harvesting phase. In comparison with the previous two terms the count of microorganisms increased significantly in the control and MIN treatments.

During the experiment the highest average count of these microorganisms was found in the control variant, while the lowest count was observed in the soil sample with the 
tomato compost enriched with the T2 strain (T2 treatment). Wolna-Maruwka et al. (2016) conducted research on the influence of analogous experimental variants on the microbiological parameters of soil under a radish plantation. During the experiment the highest count of molds was found in the soil fertilised with manure, whereas the lowest count was observed in the variant where a mineral fertiliser had been applied. These observations clearly indicate that the count of these microorganisms in soil depends on various factors, i.e. the type of fertiliser, species of a plant and its phase of development (Baetz and Martinoia, 2014; Guo, 2019).

The sanitary analysis of the soil showed that, like in the case of Trichoderma sp., in most of the experimental variants the highest statistically significant counts of fungi of the Alternaria and Fusarium genera were noted at the phase of the plants' emergence (the second term) (Figs. 2 and 3), especially in the variants where the onion waste compost had been added. During the period under analysis the lowest, statistically insignificant increase in the count of these microorganisms in relation to the control variant was noted in the experimental variants enriched with the tomato compost.

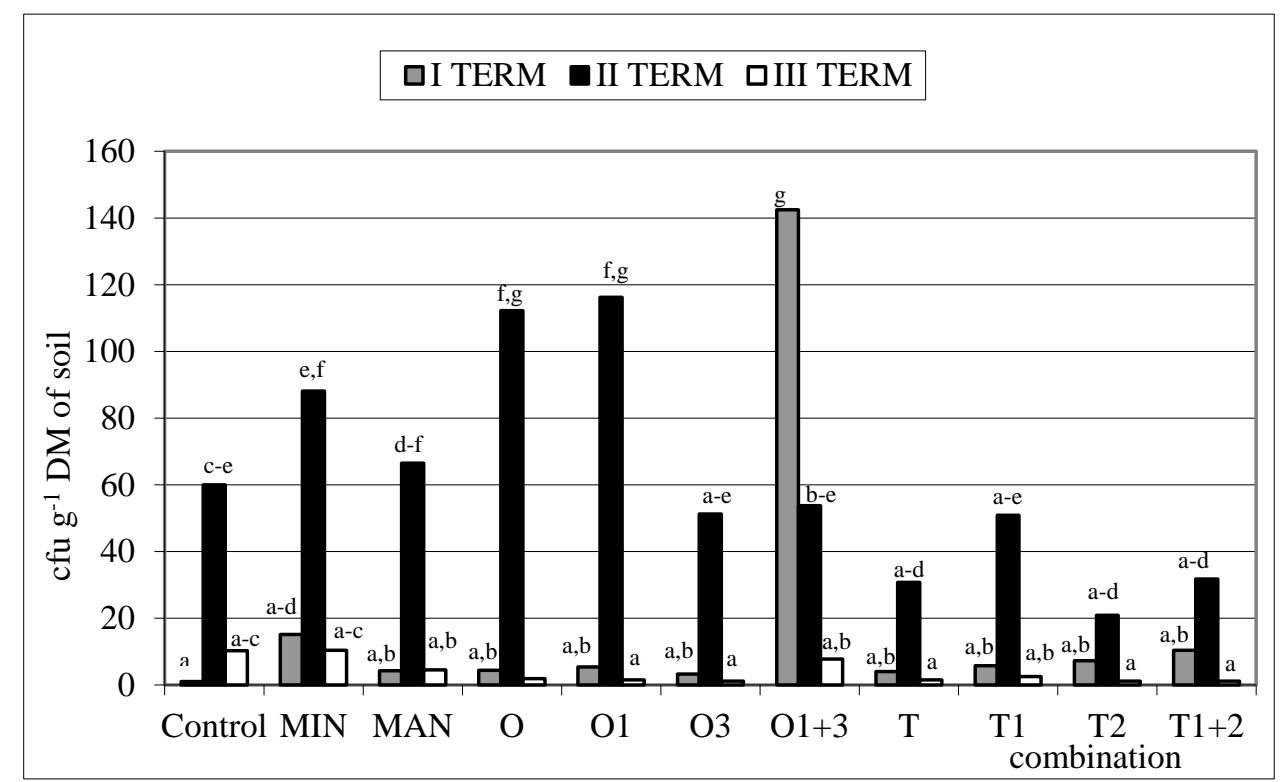

Figure 2. Changes in the count of Fusarium sp. in the soil. Explanation: The means followed by the same letters do not differ significantly at $p=0.05$; Combination: Control - no fertiliser, MIN - mineral fertiliser, $M A N$ - manure, $O$ - onion waste compost, $O 1$ - onion waste compost inoculated with strain T1, O3 - onion waste compost inoculated with strain T3, O1+3 - onion waste compost inoculated with strains $T 1$ and T3, T-tomato waste compost, T1-tomato waste compost inoculated with strain T1, T2 - tomato waste compost inoculated with strain T2, T1+2 - tomato waste compost inoculated with strains T1 and T2; Terms: $I^{\text {st }}$ - pre-sowing phase, $I^{\text {nd }}$ crop emergence phase, III ${ }^{\text {rd }}$ - harvesting phase

According to Utama et al. (2002), during the decomposition of plant residue contained in composts many different substances with strong biological properties (such as phenols, aldehydes, alcohols, essential oils, terpenes and acids) may be released and they may inhibit the development of soil microorganisms. As results from the study by Steinka and Kukułowicz (2008), caffeic acid, which can be found in tomato tissues, has strong antimicrobial properties. 


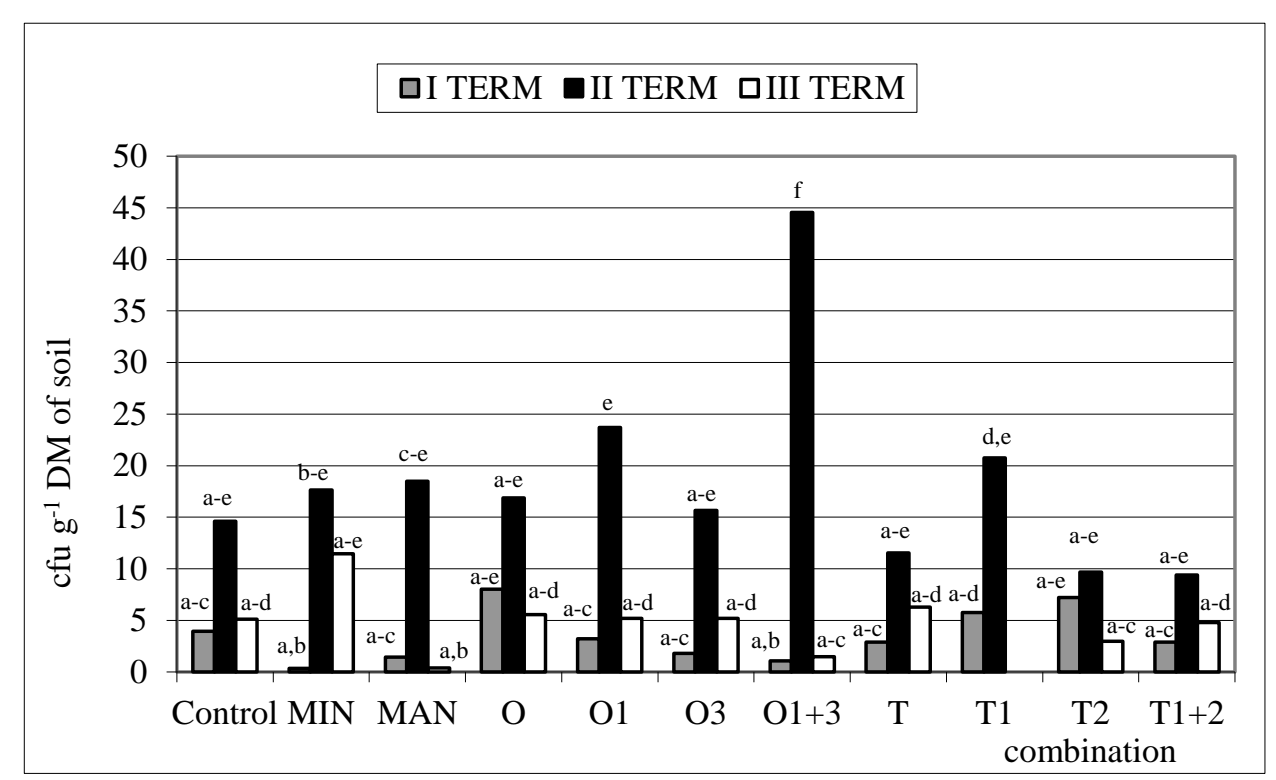

Figure 3. Changes in the count of Alternaria sp. in the soil. Explanation: The means followed by the same letters do not differ significantly at $p=0.05$; Combination: Control - no fertiliser, $M I N$ - mineral fertiliser, MAN- manure, $O$ - onion waste compost, $O 1$ - onion waste compost inoculated with strain T1, O3 - onion waste compost inoculated with strain T3, O1+3 - onion waste compost inoculated with strains $T 1$ and T3, T-tomato waste compost, T1-tomato waste compost inoculated with strain T1, T2 - tomato waste compost inoculated with strain T2, T1+2 - tomato waste compost inoculated with strains T1 and T2; Terms: $I^{\text {st }}$ - pre-sowing phase, $I I^{\text {nd }}$ crop emergence phase, III ${ }^{\text {rd }}$ - harvesting phase

Poorer proliferation of Alternaria sp. and Fusarium sp. in the variants with the tomato waste compost was additionally intensified by the effect of the Trichoderma sp. strains (especially applied separately in the case of Alternaria). The phenomenon was illustrated by the regression curves (Figs. 4 and 5).

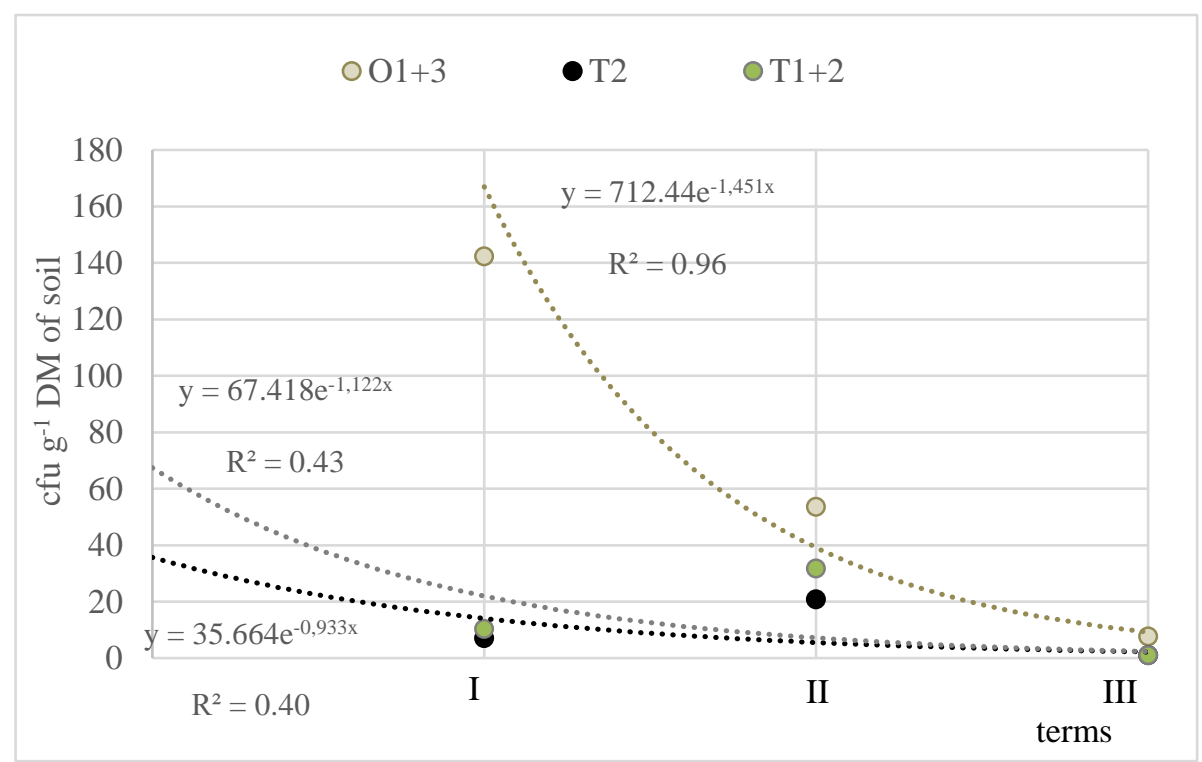

Figure 4. The dynamics of changes in the count of Fusarium sp. during the experiment 


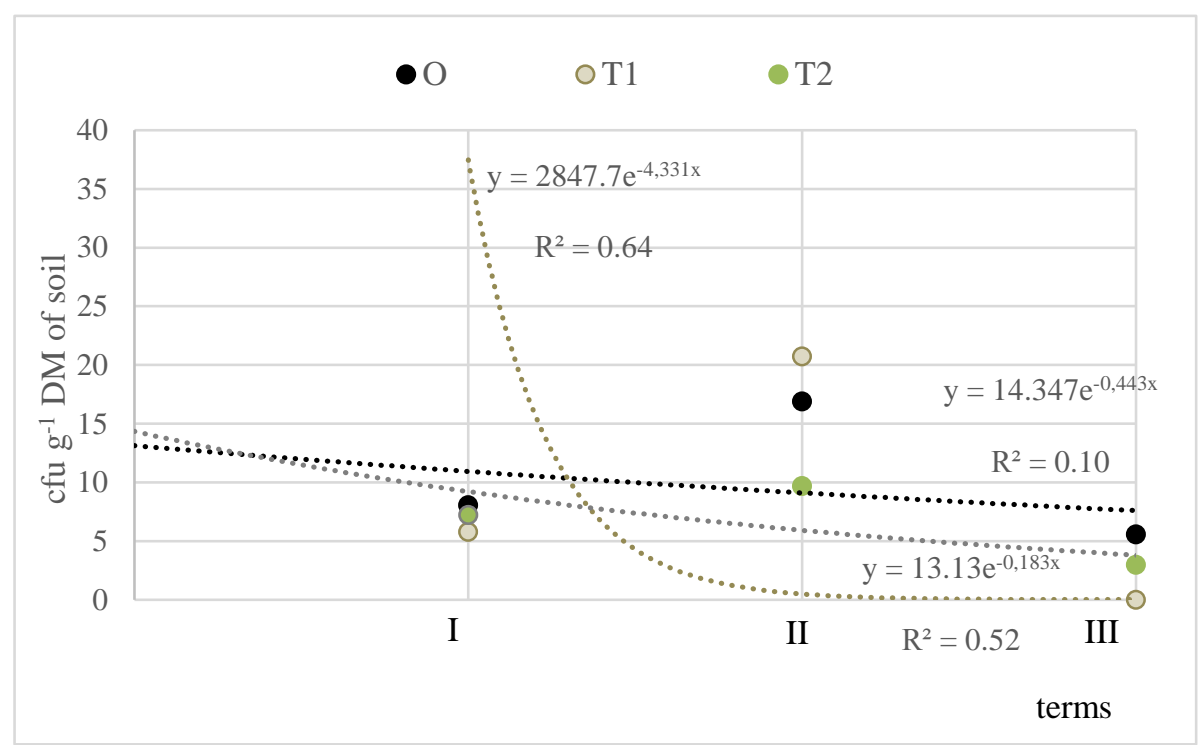

Figure 5. The dynamics of changes in the count of Alternaria sp. during the experiment

The comparison of the sanitary condition of the soil variants at the first term of analyses with the harvest phase (the third term) showed that the greatest statistically significant limitation of the development of Fusarium sp. took place in the variant enriched with the onion compost, additionally inoculated with two Trichoderma sp. strains - T1 and T3, and in the soil fertilised with the tomato compost, also with the addition of two isolates - T1 and T2 (statistically insignificant limitation at $p=0.05$ ). There was a statistically significant decrease in the count of Alternaria sp. in the soil where the tomato compost and T1 strain had been added and in the variant with the tomato compost and T2 strain (statistically insignificant limitation at $p=0.05$ ).

The analysis of changes in the activity of soil enzymes (BIF) during the study showed that the highest enzymatic activity occurred at the phase of spinach emergence (Fig. 6 ).

In most of the experimental variants (except the control and MIN treatments) these were statistically significant differences in comparison with the other two terms of analyses.

As results from the research conducted by Sasse et al. (2018) and Vallence et al. (2011), the composition of plant root secretions depends not only on the type of plant but also on the phase of its development. This finding explains the differences in the activity of soil enzymes. According to these authors, root secretions, which are rich in sugars, amino acids and vitamins, modify both the count of soil microorganisms and their activity. This fact was confirmed by the principal component analysis (Fig. 7), which showed a positive dependency between the enzyme activity and the counts of Trichoderma sp., Fusarium sp. and Alternaria sp.

In our experiment, at the second term of analyses the BIF reached the highest statistically significant values (in most cases they were statistically significant at $p=0.05$ ) in the soil samples enriched with manure (MAN) or various compost variants, especially in the ones based on tomato waste $(\mathrm{T}$ and $\mathrm{T} 1+2)$. The BIF values were greater than at the other terms of analyses. This observation was in agreement with the findings of the study by Wolna-Maruwka et al. (2017). The soil sample with the mineral fertiliser (MIN) exhibited the lowest statistically insignificant enzymatic activity. According to 
Acosta-Martinez and Tabatabai (2000), this phenomenon can be explained by the fact that although mineral fertilisation positively affects the physicochemical properties of soil, it may reduce its enzymatic activity due to the presence of easily absorbable forms of mineral compounds.

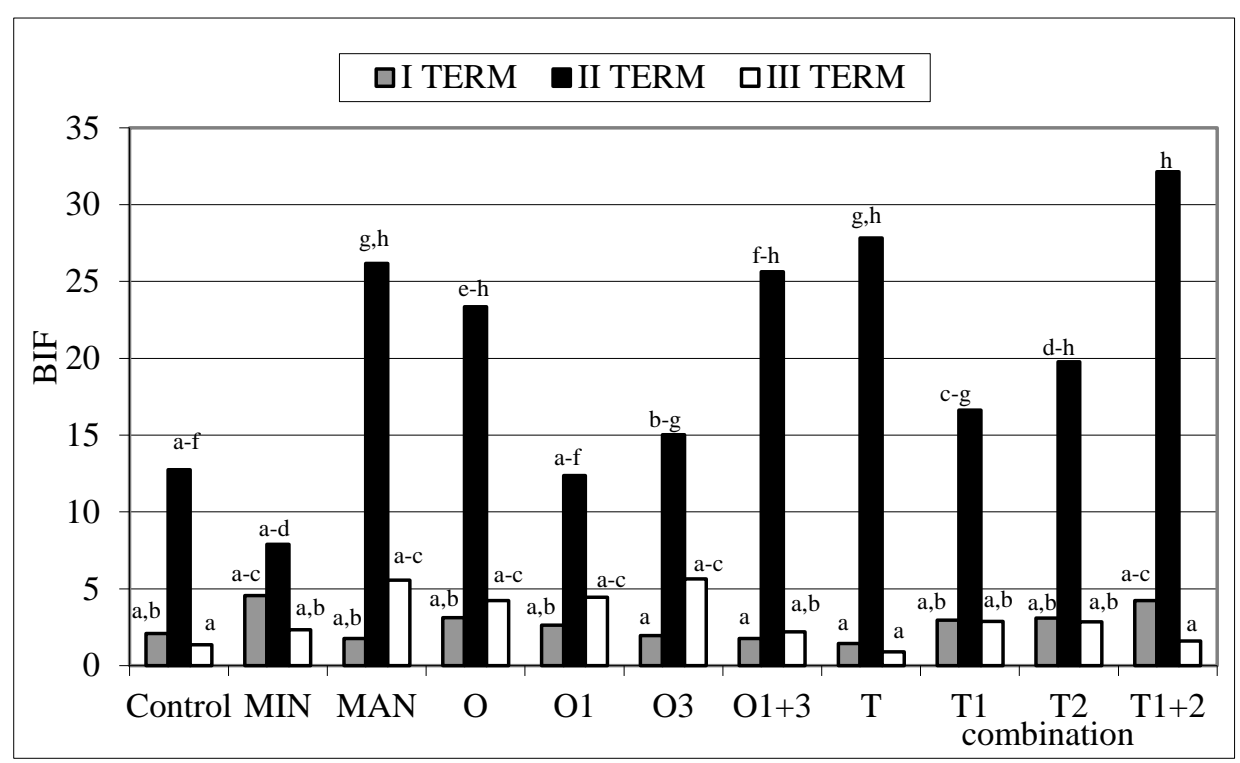

Figure 6. Changes in the Biological Index of Fertility $(B I F)$ in the soil. Explanation: The means followed by the same letters do not differ significantly at $p=0.05$; Combination: Control - no fertiliser, MIN-mineral fertiliser, MAN-manure, $O$ - onion waste compost, $O 1$ - onion waste compost inoculated with strain T1, O3 - onion waste compost inoculated with strain T3, OI+3 - onion waste compost inoculated with strains T1 and T3, T- tomato waste compost, T1 tomato waste compost inoculated with strain T1, T2 - tomato waste compost inoculated with strain T2, T1+2 - tomato waste compost inoculated with strains T1 and T2; Terms: $I^{\text {st }}$ - presowing phase, II ${ }^{\text {nd }}$ - crop emergence phase, III ${ }^{\text {rd }}$ - harvesting phase

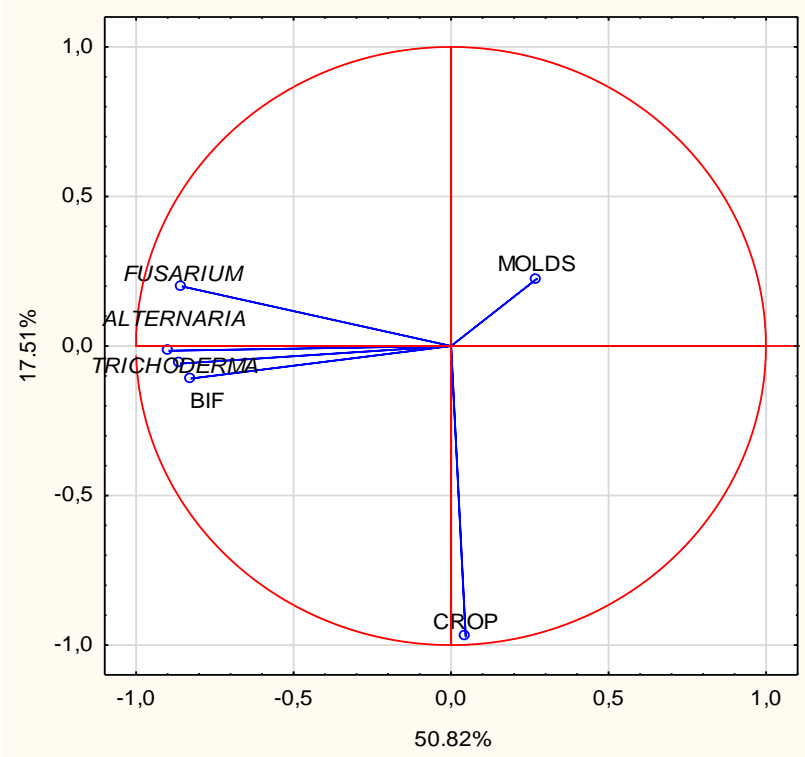

Figure 7. Dependences between the number of groups of microorganisms and the enzymatic activity in the experimental soil combinations at the consecutive terms of analyses (PCA) 
At the harvest phase (the third term) the BIF dropped rapidly in all the experimental variants, especially in the ones enriched with the tomato compost. This decrease in the soil enzymatic activity was statistically significant at $p=0.05$.

The mineral fertilisation (MIN) resulted in the highest yield $\left(8.89 \mathrm{t} \cdot \mathrm{ha}^{-1}\right)$ of the fresh mass of spinach (Fig. 8). However, the total yield of the fresh mass of spinach in the unfertilised control $\left(7.09 \mathrm{t} \cdot \mathrm{ha}^{-1}\right)$, variant with manure $\left(8.50 \mathrm{t} \cdot \mathrm{ha}^{-1}\right)$, the ones with the tomato waste compost, (T1, T2, T1+2 treatments), and the combination $\mathrm{O} 1+3$ did not differ significantly from the yield in the MIN variant application. The other types of onion waste composts $(\mathrm{O}, \mathrm{O} 1, \mathrm{O} 3)$ resulted in a statistically significant decrease in the yield in comparison with the MIN, O1+3, T1, T1+3 treatments, but did not differ from MAN, T, T2 and control variant.

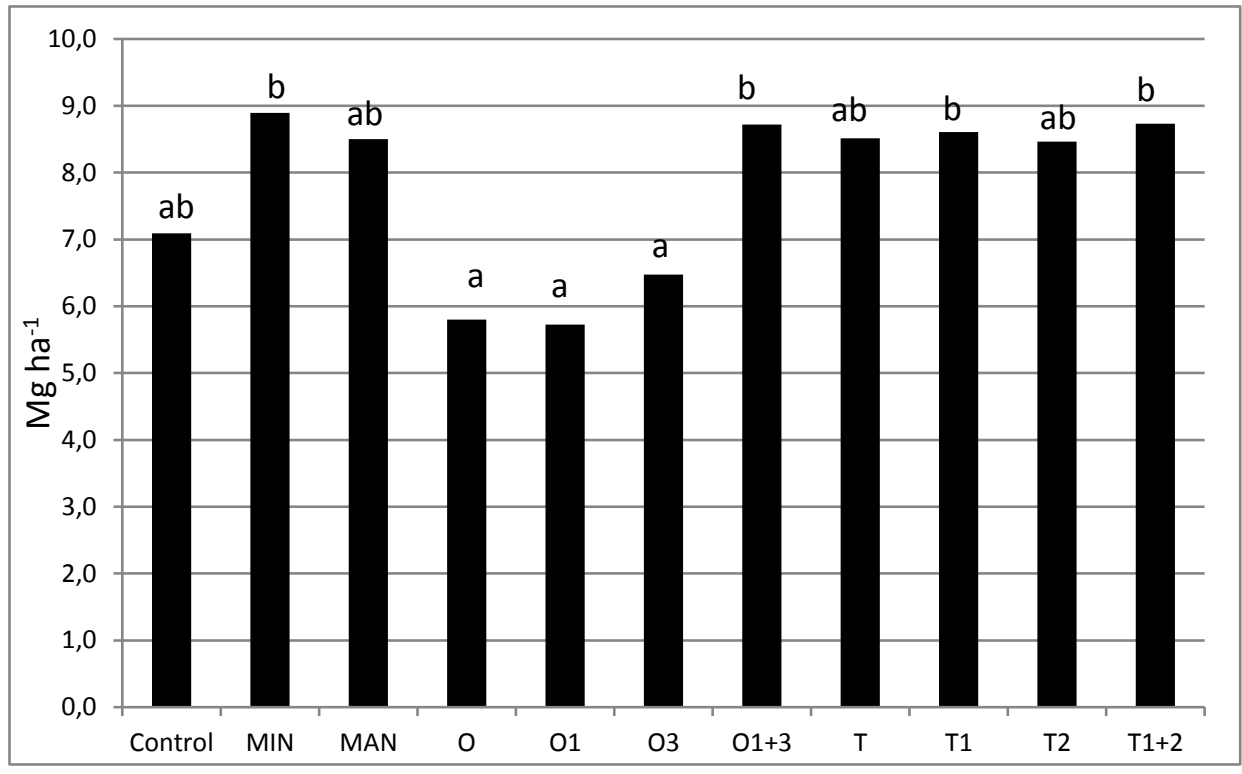

Figure 8. The average yield of spinach leaves as affected by fertilisation between 2013 and $2014\left(\mathrm{Mg} \mathrm{ha}^{-1}\right)$. Explanation: The means followed by the same letters do not differ significantly at $p=0.05$; Combination: Control - no fertiliser, MIN-mineral fertiliser, MAN-manure, $O-$ onion waste compost, $\mathrm{Ol}$ - onion waste compost inoculated with strain $\mathrm{Tl}, \mathrm{O} 3$ - onion waste compost inoculated with strain $\mathrm{T3}, \mathrm{Ol}+3$ - onion waste compost inoculated with strains $\mathrm{Tl}$ and

T3, T- tomato waste compost, T1 - tomato waste compost inoculated with strain T1, T2 tomato waste compost inoculated with strain $T 2, T 1+2$ - tomato waste compost inoculated with strains $T 1$ and $T 2$

Organic fertilisers are a valuable source of nutrients because they contain all macroand micronutrients that are necessary for plants and thus they minimise the risk of deficiency of any of them. Nitrogen is the component that usually determines the yield level. Its bioavailability in organic fertilisers is usually lower than in mineral fertilisers (Chambers et al., 2000).

The direct yield effect of solid organic fertilisers, including composts, is usually smaller than that of mineral fertilisers due to the wide $\mathrm{C} / \mathrm{N}$ ratio and the slow release of nitrogen in mineral forms. In our experiment the same dose of nitrogen was used in all the composts and manure, but there were extreme differences in the effects. The yield in the variants with manure and tomato waste compost was equal to the yield after mineral fertilisation. However, in the sample fertilised with the onion waste compost the yield 
decreased even below the level in the control variant. The situation improved significantly when a mixture of Trichoderma strains was applied into this compost. This fact lets us suppose that the composts matured at different rates, depending on their composition. The tomato waste became composted faster and gave a more mature compost, from which nutrients were released. The onion waste compost was still immature and the nutrients were not accessible to plants. Only when the two Trichoderma strains were added, maturation was accelerated and the availability of nutrients increased.

Apart from the direct yield effect, organic fertilisers significantly affect the content of humus. Humus deficiency is common in agricultural soils. It results in defective physical properties of soil, which can be improved only by applying large doses of organic matter (Piechota, 2005).

\section{Conclusions}

1. The phase of plants' development and the type of fertilisation significantly modified the microbiological and enzymatic condition of soil.

2. The application of manure resulted in the most intense proliferation of molds.

3. The most intense proliferation of Trichoderma sp. was observed in the soil enriched with the onion waste compost inoculated with the T1 and T3 strains.

4. The simultaneous application of the Trichoderma $\mathrm{T} 1$ and $\mathrm{T} 3$ strains into the onion waste compost provided the best protection of spinach against fungal pathogens of the Fusarium genus. The T1 isolate applied together with the tomato compost resulted in the most effective limitation of the development of Alternaria sp.

5. The onion compost inoculated simultaneously with the T1 and T3 strains gave the highest yield of spinach, which was comparable to the one obtained after mineral fertilisation.

6. The study proved that vegetable waste could be used as a carrier when applying Trichoderma sp. isolates into soil. It may increase the yield of crops and limit the development of some pathogens, but it is important to select the right strain of Trichoderma sp.

7. The research is strictly related with integrated crop and environment protection and provides huge prospects for organic waste management. Organic matter can be recovered as a valuable organic fertiliser and used as a carrier for selected Trichoderma sp. strains that exhibit antagonism to pathogens and promote the growth and development of plants.

Acknowledgements. The research was conducted as part of the project of the National Centre for Research and Development, No. UDA-POIG.01.03.01-00-129/09-09: 'Polish Strains of Trichoderma in Plant Protection and Organic Waste Handling'.

\section{REFERENCES}

[1] Acosta-Martinez, V., Tabatabai, M. A. (2000): Enzyme activities in a limed agricultural soil. - Biol. Fert. Soils 31: 85-91.

[2] Amann, R. I., Krumholz, L., Stahl, D. (1990): A Fluorescent-oligonucleotide probing of whole cells for determinative, phylogenetic, and environmental studies in microbiology.J. Bacteriol. 172: 762-770. 
[3] Baetz, U., Martinoia, E. (2014): Root exudates: the hidden part of plant defense. - Trends Plant Sci. 19: 90-98.

[4] Chambers, B. J., Smith, K. A., Pain, B. F. (2000): Strategies to encourage better use of nitrogen in animal manures. - Soil Use Manag. 16: 157-161.

[5] Chełkowski, J. (ed.) (1989): Fusarium, mycotoxins, taxonomy and pathogenicity; Topics in secondary metabolites. - Elsevier Science Publishers, Amsterdam, The Netherlands.

[6] Chełkowski, J., Visconti, A. (1992): Alternaria. Biology, plant diseases and metabolites. Elsevier Science Publishers, Amsterdam, The Netherlands.

[7] Colla, G., Rouphael, Y., Di Mattia, E., El-Nakhel, C., Cardarelli, M. (2015): Coinoculation of Glomus intraradices and Trichoderma atroviride acts as abiostimulant to promote growth, yield and nutrient uptake of vegetable crops. - J. Sci. Food Agr. 95: 1706-1715.

[8] Directive 2008/98/EC of the European Parliament and of the Council of 19 November 2008 on waste and repealing certain Directives.

[9] Directive 2009/128/EC of the European Parliament and of the Council establishing a framework for Community action to achieve the sustainable use of pesticides. - Official Journal of the European Union L 309, 71, 24 November 2009.

[10] Domsch, K. H., Gams, W., Anderson, T. H. (1993): Compendium of soil fungi. - Academic Press, London.

[11] Druzhinina, I., Seidl-Seiboth, V., Herrera-Estrella, A., Horwitz, B., Kenerley, C. M., Monte, E. (2011): Trichoderma: the genomics of opportunistic success. - Nat. Rev. Microbiol. 9: 749-759.

[12] Gerlach, W., Nirenberg, H. (1982): The genus Fusarium-a pictorial atlas. - Mitteilungen aus der Biologischen Bundesanstalt für Land und Forstwirtschaft. Berlin-Dahlem.

[13] Guo, X. F. (2019): Diversity and community structure of fungi in the roots of machilus pauhoi in different age groups. - Appl. Ecol. Environ. Res. 17(2): 2073-2083.

[14] Hermosa, R., Botella, L., Keck, E., Jiménez, J. Á., Montero-Barrientos, M., Arbona, V. (2011): The overexpression in Arabidopsis thaliana of a Trichoderma harzianum gene that modulates glucosidase activity, andenhances tolerance to salt and osmotic stresses. - J. Plant Physiol. 168: 1295-1302.

[15] Hermosa, R., Viterbo, A., Chet, I., Monte, E. (2012): Plant beneficial effects of Trichoderma and its genes. - Microbiology 158: 1-25.

[16] Hong, S. G., Pryor, B. M. (2004): Development of selective media for the isolation and enumeration of Alternaria species from soil and plant debris. - Can. J. Microbiol. 50: 461468.

[17] John, R. P., Tyagi, R. D., Brar, S. K., Pouleur, S., Surampalli, R. Y. (2010): Mycoparasitic Trichoderma viride as a biocontrol agent against Fusariumo oxysporum f. sp. adzuki and Pythium arrhenomanes and as a growth promoter of soybean. - Crop Prot. 29: 1452-1459.

[18] Johnson, J. L., Temple, K. L. (1964): Some Variables Affecting the Measurement of "Catalase Activity" in Soil 1. - Soil Sci. Soc. Am. J. 28: 207-209.

[19] Komada, H. (1975): Development of a selective medium for quantitative isolation of Fusarium oxysporum from natural soil. - Rev. Plant Prot. Res. 8: 114-124.

[20] López-Bucio, J., Pelagio-Flores, R., Herrera-Estrella, A. (2015): Trichoderma as biostimulant: exploiting the multilevel properties of a plant beneficial fungus. - Sci. Hortic. 196: 109-123.

[21] López-Mondéjar, R., Ros, M., Pascual, J. A. (2011): Mycoparasitism-related genes expression of Trichoderma harzianum isolates to evaluate their efficacy as biological control agent. - Biol. Control 56: 59-66.

[22] Martin, J. P. (1950): Use of acid, rose bengal and streptomycin in the plate method for estimating soil fungi. - Soil Sci. 69: 215-232.

[23] Mathys, J., De Cremer, K., Timmermans, P., Van Kerckhove, S., Lievens, B., Vanhaecke, M. (2012): Genome-wide characterization of ISR induced in Arabidopsis thaliana by Trichoderma hamatum T382 against Botrytis cinerea infection. - Front. Plant Sci. 3: 1-25. 
[24] Minelgaitè, A., Genovaitè, L. (2019): Waste problem in European Union and its influence on waste management behaviours. - Sci. Total Environ. 667: 86-93.

[25] Piechota, T. (2005): Impact of long-term effects of plant succession and fertilization systems on the soil's physical properties. - Fragm. Agron. 2: 158-166.

[26] Piegza, M., Stolaś, J., Kancelista, A., Witkowska, D. (2009): Influence of Trichoderma strains on the growth of pathogenic moulds in biotic test on untypical carbon sources. Acta Sci. Pol. Biotechnol. 8: 3-14.

[27] PN-ISO 10381-2:2007 Soil quality - Collecting Samples - Part 2: The rules of collection techniques.

[28] Regulation of the Minister of Agriculture and Rural Development on the Reduction of the Mass of Biodegradable Municipal Waste to Be Landfilled and the Method of Calculation of the Limits of This Mass of Waste, 25 May 2012. - Journal of Laws of 2012, item. 676.

[29] Regulation of the Minister of Agriculture and Rural Development on Integrated Crop Protection Requirements of 18 April 2013. - Journal of Laws of 2013, item 505.

[30] Regulation of the Minister of Agriculture and Rural Development on Recycling R10 of 20 January 2015. - Journal of Laws of 2015, item 132.

[31] Sasse, J., Martinoia, E., Northen, T. (2018): Feed your friends: do plant exudates shape the root microbiome? - Trends Plant Sci. 23: 25-41.

[32] Siddiquee, S., Yusof, N. A., Salleh, A. B., Tan, S. G., Bakar, F. A., Heng, L. Y. (2010): DNA hybridization based on Trichoderma harzianum gene probe immobilization on self-assembled monolayers on a modified gold electrode. - Sensors and Actuators B-Chem 147: 198-205.

[33] Smolińska, U., Kowalska, B., Kowalczyk, W., Szczech, M. (2014): The use of agro-industrial wastes as carriers of Trichoderma fungi in the parsley cultivation. - Sci. Hortic. 179: 1-8.

[34] Statistics Poland. (2018): Statistical analyses. - Municipal infrastructure in 2017 - Warsaw.

[35] Stefanic, G., Eliade, G., Chirnogeanu, I. (1984): Researches concerning a biological index of soil fertility. - 5. Symposium on Soil Biology, Feb 1981 Jassy (Romania).

[36] Steinka, I., Kukułowicz, A. (2008): The biostatic influence of plant pulp and solutions on Staphylococci. - Bromat. Chem. Toksykol. 2: 191-196.

[37] Thalmann, A. (1968): Zur methodik der bestimmung der dehydrogenase aktivität in boden mittels Triphenyltetrazoliumchlorid (TTC). - Landwirt Forsch 21: 249-258.

[38] Utama, I. M. S., Wills, R. B. H., Ben-Yehoshua, S., Kuek, C. (2002): In vitro efficacy of plant volatiles for inhibiting the growth of fruit and vegetable decay microorganisms. - J. Agric. Food Chem. 50: 6371-6377.

[39] Vallance, J., D'eniel, F., Le Floch, G., Gu'erin-Dubrana, L., Blancard, D., Rey, P. (2011): Pathogenic and beneficial microorganisms in soilless cultures. - Agron. Sustain. Dev. 31: 191-203.

[40] Wawrzyniak, J., Waśkiewicz, A. (2014): Ochratoxin A and citrinin production by Penicillium verrucosum on cereal solid substrates. - Food Addit. Contam. A. 31: 139-148.

[41] Wojtkowiak-Gębarowska, E. (2006): The Mechanisms of Controlling Soil Phytopathogens by Fungi of the Trichoderma Genus. - Postępy Mikrobiologii 45: 261-273.

[42] Wolna-Maruwka, A., Piechota, T., Kosicka-Dziechciarek, D., Szczech, M., Niewiadomska, A., Dach, J. (2016): A mycological analysis of soil fertilised with vegetable waste composts under a radish (Raphanus sativus) plantation. - J. Res. App. Agric. Eng. 61: 223-229.

[43] Wolna-Maruwka, A., Piechota, T., Dach, J., Szczech, M., Szczerbal, I., Niewiadomska, A., Budka, A., Gaj, R. (2017): The influence of Trichoderma on the phytosanitary status of soil and yield of red beets (Beta vulgaris L. subsp. vulgaris). - Pol. J. Environ. Stud. 26: 847-859. 